\title{
Viral Tracing Identifies Parallel Disynaptic Pathways to the Hippocampus
}

\author{
Judy A. Prasad and Yogita Chudasama \\ Department of Psychology, McGill University, Montreal, Quebec H3A 1B1, Canada
}

Electrophysiological and lesion studies in rodents have shown that the dorsal (septal) and ventral (temporal) segments of the hippocampus have functional specializations that can be understood in terms of their anatomical connections with distinct brain areas. Here we explore the circuitry associated with the hippocampus using the pseudorabies virus-Bartha strain (PRV-Bartha) tracer in the rat to examine both direct (first-order) and indirect (second-order) projections to the hippocampus. Based on analysis of PRV-Bartha infection density, we demonstrate two parallel pathways from the limbic cortex to the hippocampus. A dorsal "spatial cognition" pathway provides disynaptic input from the retrosplenial, anterior cingulate, and orbital cortex to the dorsal hippocampus, with potential synaptic relays in the anterior thalamic nuclei and dorsolateral entorhinal cortex. A ventral "executive control" pathway provides disynaptic input from the prelimbic, infralimbic, and orbital cortex to the ventral hippocampus, with potential synaptic relays in the midline thalamic nuclei and the rostral caudomedial entorhinal cortex. These data suggest a new anatomical framework for understanding the functional interactions between the cortex and hippocampus, especially in cognitive disorders that involve both structures, such as frontotemporal dementia.

\section{Introduction}

Cognition in humans and animals involves a continual exchange of information between remote brain areas mediated by longrange axonal projections. Emerging methods such as diffusion weighted imaging or resting state functional connectivity can be used to visualize or approximate some of these pathways in humans. However, none are as precise and reliable as tract tracing in experimental animals. Certain viral tracers, such as the pseudorabies virus-Bartha strain (PRV-Bartha), provide the opportunity to investigate anatomical pathways embedded in functional circuits in more detail than conventional tracers. This is because the amplification of the virus and retrograde transport across multiple synapses allows for an evaluation of indirect, as well as direct, anatomical projections. We use this method here to investigate monosynaptic and disynaptic inputs to the dorsal and ventral divisions of the rat hippocampus.

The mammalian hippocampus sends projections to and receives projections from cortical and subcortical brain regions involved in a range of functions. Consequently, hippocampal damage in animals and humans can result in a wide range of

\footnotetext{
Received Oct. 30, 2012; revised April 3, 2013; accepted April 5, 2013.

Author contributions: J.A.P. and Y.C. designed research; J.A.P. and Y.C. performed research; J.A.P. analyzed data; J.A.P. and Y.C. wrote the paper.

This work was supported by Grant 341600 from the Natural Sciences and Engineering Research Council of Canada and Grant 14033 from the Canadian Foundation for Innovation Leaders Opportunity Fund. We thank Drs. J. Patrick Card and Lynn W. Enquist for providing PRV-Bartha and antibodies, and technical advice concerning their use. We also thank Peter Antkowiak, Nora Butkute, and Shivani Bhat for their help with cell counting, and Emma Mitchell and Alan Cook for their help with histology. We are very grateful to Dr. David A. Leopold for helpful comments on this manuscript.

The authors declare no competing financial interests.

Correspondence should be addressed to Dr. Yogita Chudasama, Department of Psychology, McGill University, Montreal, QC H3A 1B1, Canada. E-mail: yogita.chudasama@mcgill.ca.

DOI:10.1523/JNEUROSCI.5072-12.2013

Copyright $\odot 2013$ the authors $\quad 0270-6474 / 13 / 338494-10 \$ 15.00 / 0$
}

behavioral deficits (Chudasama et al., 2009; Mariano et al., 2009; Small et al., 2011; Abela et al., 2013). The nature of the impairment depends, in part, on the location of the lesion along the hippocampal septotemporal axis (dorsoventral axis in the rodent) (Bannerman et al., 1999; Fanselow and Dong, 2010). In rats, damage to the dorsal hippocampus (dHC) affects spatial cognition, reflecting its input from temporal areas such as the caudal entorhinal cortex known to be involved in the encoding of space (Hafting et al., 2005). In contrast, damage to the ventral hippocampus (vHC) affects aspects of emotion (Bannerman et al., 1999; Pentkowski et al., 2006) and leads to impairments in executive control, a function normally associated with the prefrontal cortex (Floresco et al., 1997; Howland et al., 2008; Abela and Chudasama, 2013; Abela et al., 2013). Recent work highlights the interaction between the $\mathrm{vHC}$ and ventral prefrontal cortex, showing that crossed lesions of the two structures result in impulsive and compulsive behavior, whereas unilateral combined lesions do not (Chudasama et al., 2012).

The hippocampal CA1 field projects directly to a number of cortical areas, including the medial prefrontal, orbital, retrosplenial (RSP), and cingulate cortex (Hoover and Vertes, 2007). These projections are not reciprocated (Room et al., 1985; Sesack et al., 1989), suggesting that the hippocampus can influence activity in these areas, but not vice versa. It is possible that these same cortical structures influence the hippocampus via relays in the thalamus (Wouterlood et al., 1990) or entorhinal cortex (Witter and Groenewegen, 1984). Identifying relay pathways is of great importance for understanding circuit function (Thompson and Swanson, 2010), and is greatly facilitated with viral tracers that delineate second-order connections. Here we used PRVBartha to identify disynaptic pathways from limbic and prefrontal cortex to hippocampal area CA1. Following virus injections at two distinct locations along the hippocampal septotemporal axis, 


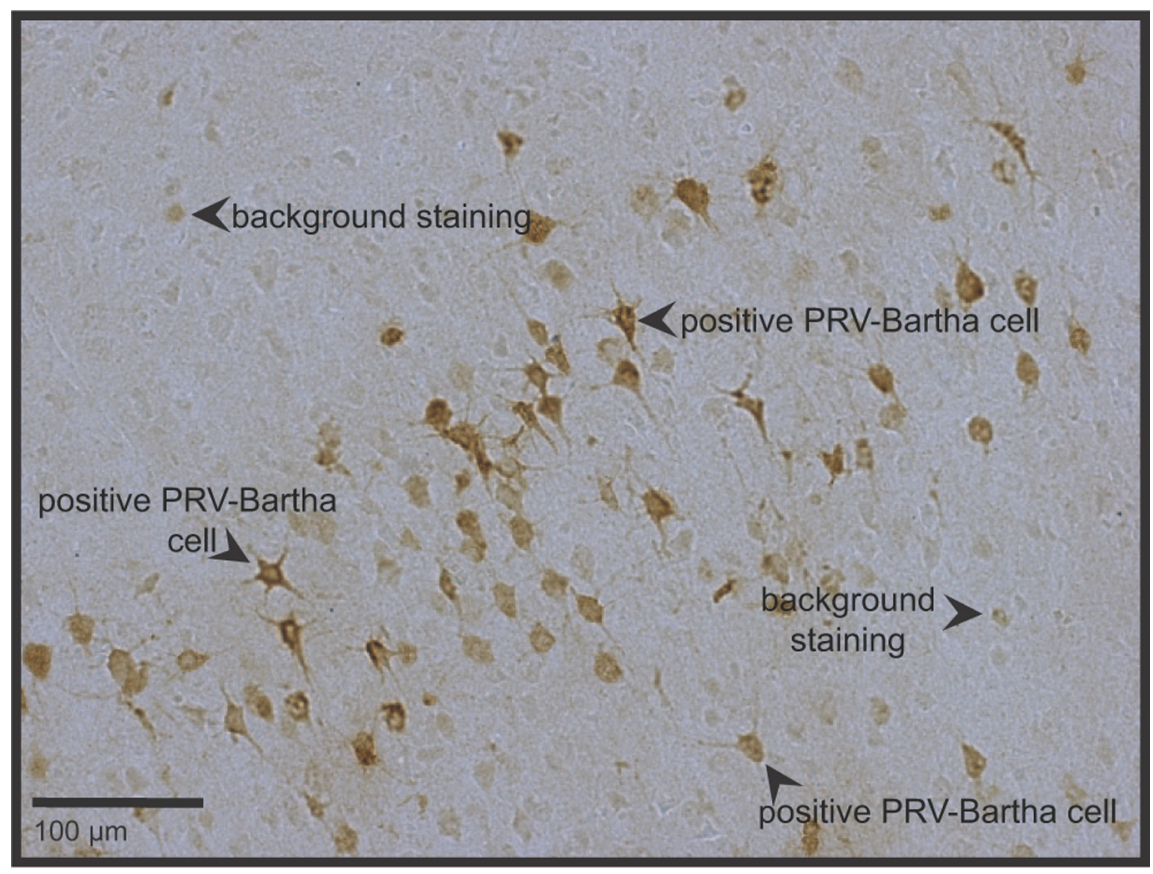

Figure 1. Example of distribution of viral immunoreactivity in orbital prefrontal cortex $60 \mathrm{~h}$ after injection of PRV-Bartha into the $\mathrm{dHC}$ (viewed at $20 \times$ magnification). Viral antigens were targeted with a rabbit polyclonal antibody generated against the acetone-inactivated virus (see Materials and Methods). Note that viral immunoreactive cells (i.e., positive PRV-Bartha-infected cells) are marked with an intense brown coloration and are clearly distinguishable from noninfected cells (background staining).

we provide evidence for parallel disynaptic pathways to the dorsal and ventral hippocampus, with potential anatomical relays in the thalamus and entorhinal cortex.

\section{Materials and Methods}

PRV-Bartha is a swine $\alpha$-herpesvirus that is widely used for retrograde transneuronal tracing for multisynaptic circuitry in rats (Card et al., 1993; O’Donnell et al., 1997; Chen et al., 1999). The procedures for growing and harvesting PRV-Bartha have been published in detail previously (Enquist and Card, 1996). Several reviews provide detailed descriptions of the mechanisms that underlie PRV-Bartha invasion, replication, and multisynaptic transmission (Pomeranz et al., 2005).

Subjects. Male Sprague Dawley rats $(250-300 \mathrm{~g})$ were used for this study. Food and water was available ad libitum under a $12 \mathrm{~h}$ light/dark cycle. All experimental procedures were approved by the McGill University Animal Care and Use Committee and were performed in accordance with the guidelines of the Canadian Council on Animal Care. In compliance with Laboratory Biosafety Guidelines (third edition, 2004) stipulated by the Public Health Agency of Canada, injections of PRV-Bartha were conducted in a Biosafety Level 2 containment facility.

Surgery and injection procedure. Each rat was anesthetized with isoflurane (4-5\% induction, $1-3 \%$ maintenance) and secured in a stereotaxic frame (David Kopf Instruments). The scalp was retracted and a hole was drilled into the skull directly above the injection site. A total of $0.1 \mu \mathrm{l}$ of PRV-Bartha $\left(4.5 \times 10^{8} \mathrm{pfu} / \mathrm{ml}\right)$ was injected unilaterally (right hemisphere) into the $\mathrm{dHC}$ (anterior-posterior, $-4.20 \mathrm{~mm}$; medial-lateral, $\pm 2.00 \mathrm{~mm}$; dorsal-ventral, $-2.80 \mathrm{~mm}$ ) or $\mathrm{vHC}$ (anterior-posterior, $-5.28 \mathrm{~mm}$; medial-lateral, $\pm 5.0 \mathrm{~mm}$; dorsal-ventral, $-7.2 \mathrm{~mm}$ ) according to stereotaxic coordinates of Paxinos and Watson (2005). Dorsalventral readings were taken from the dural surface. The virus was injected over 4 min using a $0.5 \mu \mathrm{l} \mathrm{SGE} \mathrm{precision} \mathrm{microsyringe} \mathrm{(Canadian} \mathrm{Life}$ Science) and allowed to diffuse for an additional $4 \mathrm{~min}$ to prevent reflux of the virus up the cannula tract. The syringe was then carefully removed, and the scalp was sutured. When rats were sufficiently mobile, they were returned to their home cages.

Perfusion and tissue processing. Animals were deeply anesthetized with pentobarbital (100 mg/kg, i.p.) and perfused transcardially with
$0.9 \%$ saline followed by a periodate-lysineparaformaldehyde (PLP) fixative. Brains were extracted and postfixed in PLP at $4^{\circ} \mathrm{C}$ for $48 \mathrm{~h}$. Cryostat sectioned brains were cut in the coronal plane, rostrocaudally. We were unable to obtain the most posterior sections of the occipital pole, which comprises the caudal extreme of the entorhinal cortex. The sections were transferred to a $30 \%$ sucrose solution $\left(4^{\circ} \mathrm{C}\right)$ for $48 \mathrm{~h}$ before being flash frozen in isopentane and stored at $-20^{\circ} \mathrm{C}$. Coronal sections $(40 \mu \mathrm{m}$ thick) were collected in series. All tissue was stored free floating at $-20^{\circ} \mathrm{C}$ in a cryoprotectant solution until it was ready for processing. For each animal, one tissue series was processed using a standard cresyl violet staining procedure to identify and trace cytoarchitectonic regions of interest (ROIs). A second, adjacent series of tissue was processed using a free-floating immunohistochemistry protocol (immunoperoxidase staining) as described below.

Tissue sections were examined with a Zeiss AxioImager A1 microscope and Bioquant Life Science Image Analysis Software. The specific thalamic and cortical ROIs traced from cresyl violet sections were overlaid onto the immunoperoxidase stained tissue. For each ROI, the numbers of positive PRV-Bartha-infected cells were identified (Fig. 1) and counted in every sixth section $(20 \times$ magnification). We then calculated the density of infection for each ROI in relation to its area (i.e., number of infected cells/area of the ROI in micrometers squared).

Immunohistochemistry. The immunoperoxidase procedure was conducted at ambient room temperature $\left(22-24^{\circ} \mathrm{C}\right)$. Sections were rinsed (three times, $10 \mathrm{~min}$ per wash) with fresh $0.0025 \mathrm{~m} \mathrm{PBS,} \mathrm{pH} \mathrm{7.4-7.6,}$ treated with dilute peroxide solution for $15 \mathrm{~min}(0.6 \%$ peroxide in $0.0025 \mathrm{M}$ PBS) to quench any endogenous peroxidases within the tissue, and rinsed again in $0.0025 \mathrm{M}$ PBS (three times, $5 \mathrm{~min}$ per wash). Sections were then incubated in a blocking solution containing $10 \%$ normal goat serum (NGS) and $0.3 \%$ Triton-X diluted in $0.0025 \mathrm{~m}$ PBS for $25 \mathrm{~min}$. The tissue was then transferred to the primary antibody solution (rabbit antiPRV IgG, diluted $1: 10,000$ in a solution of $10 \%$ NGS in $0.0025 \mathrm{M}$ PBS) and incubated for $2 \mathrm{~h}$. Following three rinses in $0.0025 \mathrm{~m}$ PBS ( 5 min per wash), the sections were further incubated for $30 \mathrm{~min}$ in a solution of biotinylated goat anti-rabbit IgG, diluted in 10\% NGS in 0.0025 M PBS. Following another three washes in 0.0025 м PBS (5 min per wash), sections were incubated for $30 \mathrm{~min}$ using the avidin-biotin peroxidase procedure as per the Vectastain Elite ABC-HRP kit (Vector Laboratories). Sections were rinsed in $0.0025 \mathrm{M}$ PBS (three times, $10 \mathrm{~min}$ per wash) and then incubated in a dilute solution of the chromagen diaminobenzadine, prepared using the HRP Substrate Kit (Vector Laboratories). Sections were incubated for 3-10 min until the colorized signal was visualized within the tissue. Immediately after the signal was detected, all sections were rinsed in fresh $0.0025 \mathrm{M}$ PBS (three times, $5 \mathrm{~min}$ per wash) to completely remove any excess of the chromagen. Sections were then mounted on gelatin-coated slides and left to air dry overnight. All slides were dehydrated using a graded alcohol series and xylene, after which they were mounted with Permount (Fisher Scientific) and coverslipped.

Antibody specificity. The primary antibody used to target the PRVBartha was derived from an antiserum raised against acetone-inactivated PRV. The rabbit anti-PRV polyclonal IgG (Rb 133/134) was provided to us courtesy of Dr. L. Enquist (Center for Neuroanatomy with Neurotropic Viruses, National Center for Research Resources, Bethesda, MD). We tested the specificity of this antibody by running the immunohistochemistry protocol on tissue from animals that had not been inoculated with PRV-Bartha. These sections were void of any labeling, 


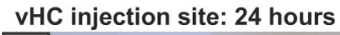
D

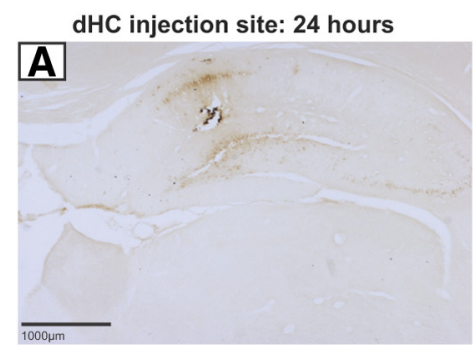

dHC injection sites: 48 hours

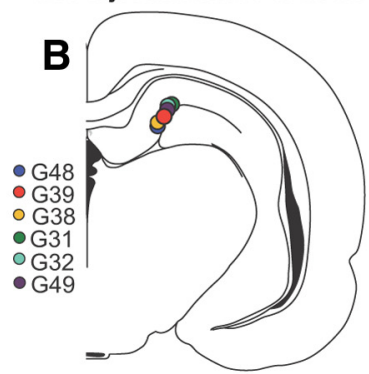

dHC injection sites: 60 hours
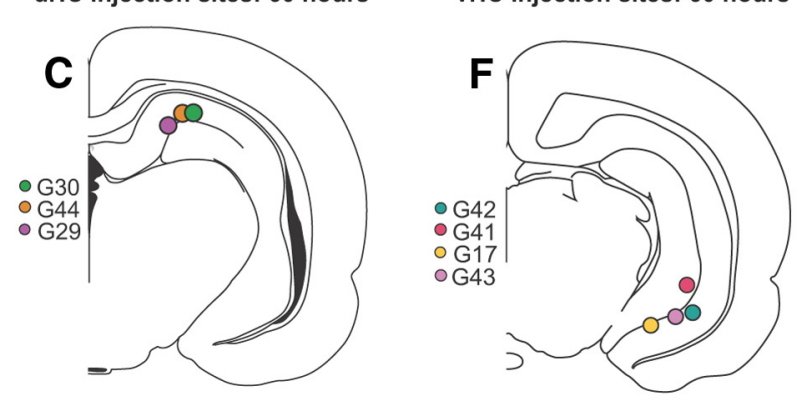

Figure 2. $\boldsymbol{A}, \boldsymbol{D}$, Representative bright-field photomicrographs $(2.5 \times$ magnification) show diffusion of PRV-Bartha from injection sites in the $\mathrm{dHC}(\boldsymbol{A})$ and $\mathrm{vHC}(\boldsymbol{D}) 24 \mathrm{~h}$ after inoculation. Note that the injection site is confined to the $C A 1$ field, and viral immunoreactivity is restricted to the area surrounding the injection cannula. $\boldsymbol{B}, \boldsymbol{C}, \boldsymbol{E}, \boldsymbol{F}$, Placement of injection sites in the $\mathrm{dHC}$ $(\boldsymbol{B}, \boldsymbol{C})$ and $\mathrm{vHC}(\boldsymbol{E}, \boldsymbol{F})$ are presented schematically for animals that were perfused 48 and $60 \mathrm{~h}$ after inoculation, respectively. Colors represent different animals in each group.

confirming that the antibody was specific to detecting the PRV-Bartha antigen.

\section{Results}

Animals were injected in either $\mathrm{dHC}$ or $\mathrm{vHC}$ and were killed at $24 \mathrm{~h}(\mathrm{dHC}, n=4$; vHC, $n=4), 48 \mathrm{~h}(\mathrm{dHC}, n=6$; vHC, $n=6)$, or $60 \mathrm{~h}(\mathrm{dHC}, n=3$; vHC, $n=4)$. Animals killed at $24 \mathrm{~h}$ did not show retrograde transport of the virus beyond the injection site. The analysis of the density and distribution of viral infection in animals that were killed at 48 and $60 \mathrm{~h}$ allowed us to determine first- and second-order projection sites, respectively. We first established monosynaptic transport to the thalamus and the entorhinal cortex as both of these regions have been shown previously to provide direct input to the hippocampal CA1 region. We then identified a number of sites that were labeled at the longer survival time corresponding to disynaptic transport.

The injection sites were highly circumscribed to the CA1 field of the dorsal or ventral hippocampus, with viral immunoreactivity confined to the area immediately surrounding the injection cannula. The photomicrographs in Figure 2, $A$ and $D$, show that at $24 \mathrm{~h}$ after inoculation, there was minimal diffusion of PRV-
Bartha from the focal injection site, and positive PRV-Barthainfected cells were not present in any other region including the subiculum, CA3 or CA2 fields, amygdala, entorhinal cortex, or any region of the cerebral cortex. In contrast, the density and pattern of viral infection and transport of PRV-Bartha at postinoculation times of 48 and $60 \mathrm{~h}$ indicated that these time periods were most effective for characterizing first- and second-order infection, respectively.

The location of the injection sites are illustrated in Figure 2, which demonstrates their position on standard coronal sections. In coronal sections, which are more tangential than transverse, it is difficult to define with specificity the exact distal and proximal topology of the injection sites (Amaral and Witter, 1989; Henriksen et al., 2010). However, according to the proximodistal terminology provided by Amaral (1993), we estimate that all injections in the $\mathrm{dHC}$ were restricted to the distal CA1 region of the hippocampus at the most septal tip of the structure (Fig. 2A-C) located closest to the subiculum. Similarly, the ventrally located injections appeared to be confined to the distal CA1 region closest to the subiculum. Although the CA1 injection in cases G9, G52 ( 48 h group; Fig. 2 E), and G41 (60 h group; Fig. 2 F) encroached the molecular layer of the dentate gyrus, the pattern of labeling at long survival times was similar to that for those animals with restricted CA1 injections. In all cases that were analyzed, the injections did not encroach the subiculum, CA2, or CA3 fields. In the following sections, we describe the pattern of disynaptic labeling in the limbic and prefrontal cortex followed by the pattern of monosynaptic labeling in the thalamus and entorhinal cortex.

\section{Disynaptic transport to limbic and prefrontal cortex (60 h survival)}

At $60 \mathrm{~h}$ after inoculation, specific cortical regions showed a high density of labeled cells for each of the injection locations. Based on previous findings (O'Donnell et al., 1997; Carr et al., 1999), we interpreted this labeling to reflect disynaptic retrograde transport of the virus, and thus to indicate areas that provide indirect input to the hippocampus. Note that there was little if any infection in the prefrontal or limbic cortical areas at $48 \mathrm{~h}$ after inoculation (see later). In all cases, while the density of labeling was stronger in the ipsilateral than contralateral hemisphere, the disynaptic labeling of the cortex was considerably more similar between the two hemispheres than the monosynaptic labeling in either the thalamus or entorhinal cortex.

\section{Labeling in the prefrontal cortex}

Large numbers of infected neurons were observed in the prefrontal cortex. Of the prefrontal regions exhibiting disynaptic labeling, some showed overlap between the $\mathrm{vHC}$ and $\mathrm{dHC}$ injections, whereas others did not. Both injections showed some degree of labeling in the prelimbic (PL) cortex, the infralimbic (IL) cortex and the medial, ventral, and lateral divisions of the orbitofrontal cortex. The labeling started very anterior in the orbital divisions with a slightly greater density of infected neurons in the $\mathrm{dHC}$ injected animals at this level. Moving more caudally, however, the labeling in the orbital divisions was similar for the two injection groups (Fig. $3 A, B$ ). The most notable difference between the $\mathrm{dHC}$ - and vHC-injected animals was the distribution of the retrogradely labeled cells along the dorsoventral axis of the medial prefrontal cortex (Heidbreder and Groenewegen, 2003). The dHC injections, which were highly comparable, as shown in the inset above Figure 3, resulted in more labeling in the dorsal anterior cingulate cortex (pregenual $\mathrm{Cg} 1 / \mathrm{Cg} 2$ ) and the dorsal part of the PL cortex (dPL). Among the vHC cases, the pattern of 


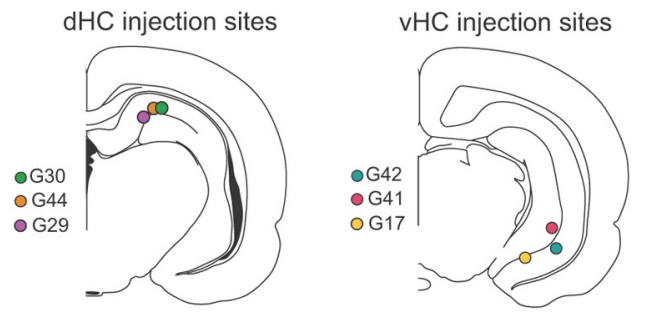

Disynaptic Labeling
in Prefrontal Cortex
A
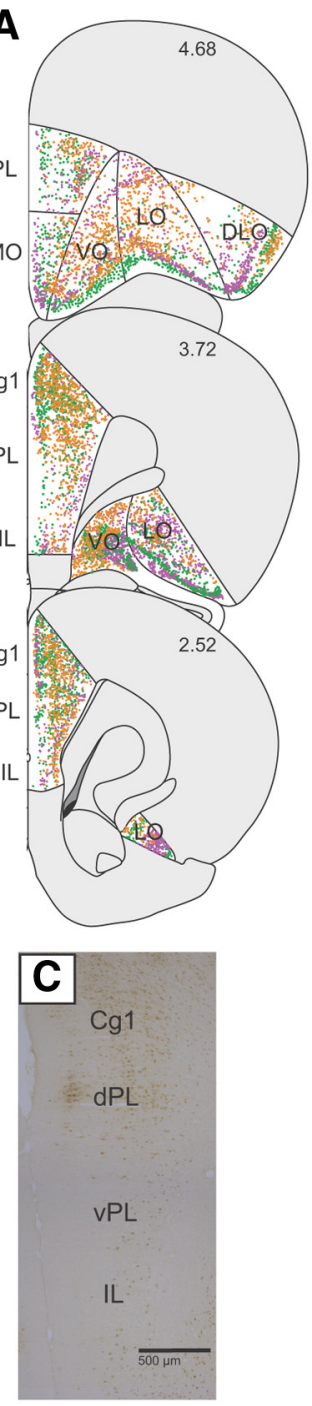

B
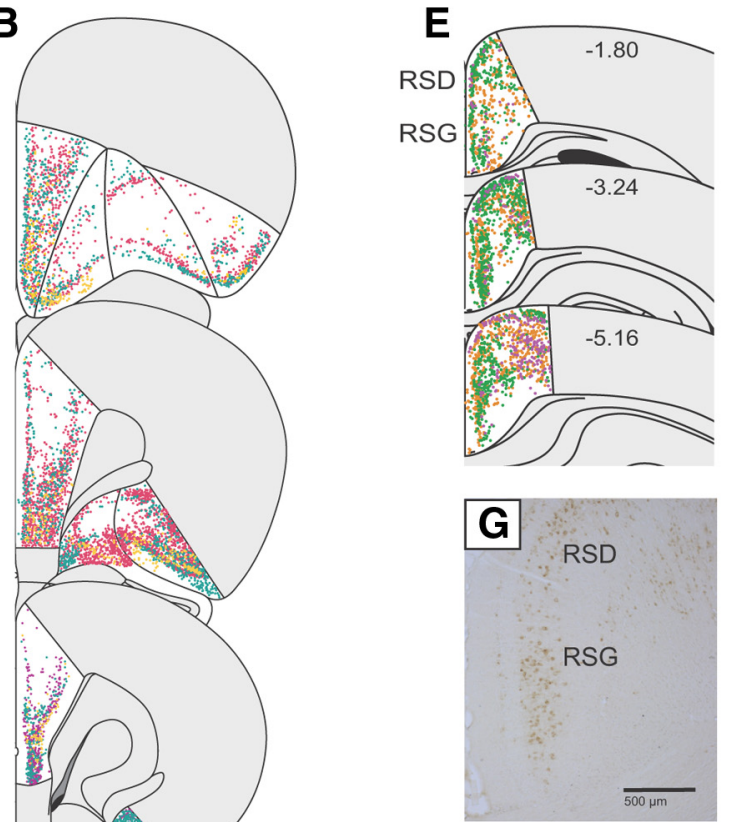

Disynaptic Labeling

in Retrosplenial Cortex
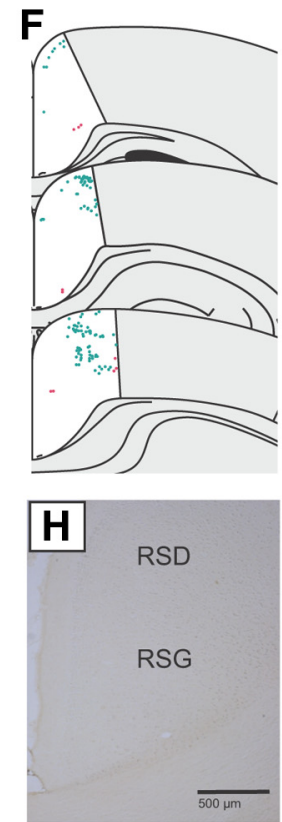

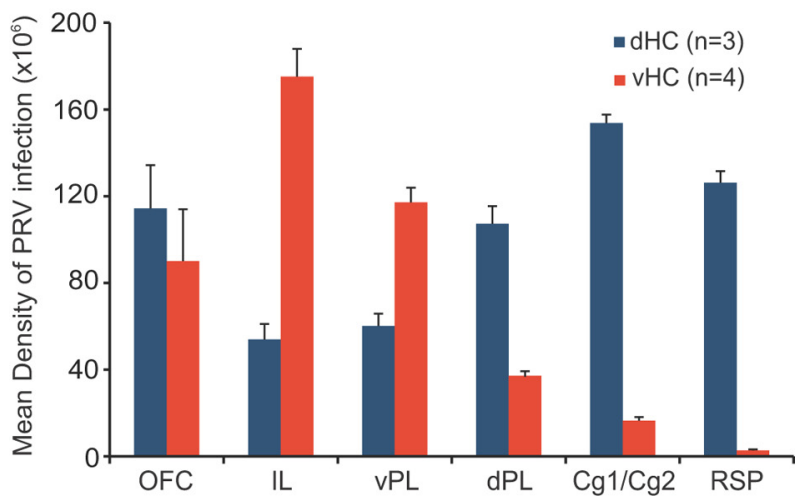

Figure 3. Distribution of positive PRV-Bartha-infected cells in the prefrontal cortex and retrosplenial cortex $60 \mathrm{~h}$ after inoculation. Colors represent different animals. There was considerable infection in the prefrontal cortex for both $\mathrm{vHC}$ and $\mathrm{dHC}$ cases, especially in the caudal divisions of the orbitofrontal cortex. $\boldsymbol{A}$, In $\mathrm{dHC}$ cases, the pattern of infection was confined to the dorsal prefrontal cortex, particularly the dorsal pregenual anterior cingulate (area $\mathrm{Cg} 1$ ) and the most dorsal portion of the prelimbic cortex. $\boldsymbol{B}$, In the vHC cases, considerable labeling was visible in the vPL and particularly in the IL. Notice how the dorsal prefrontal cortex (dPL and area $(\mathrm{g} 1)$ is relatively spared of infection in these vHC cases. $\boldsymbol{C}, \boldsymbol{D}$, Photomicrographs $(5 \times$ magnification) show distribution of virus-infected neurons along the dorsoventral axis of the right prefrontal cortex following injections in representative $\mathrm{dHC}$ and vHC cases, respectively. $\boldsymbol{E}$, $\boldsymbol{F}$, Patterns of infection in the RSP cortex is presented schematically for cases with virus injections in the $\mathrm{dHC}(\boldsymbol{E})$ and $\mathrm{vHC}(\boldsymbol{F})$. Both dysgranular and granular divisions of the RSP cortex were densely infected in animals with $\mathrm{dHC}$ injections, but there was a virtual absence of infected neurons in the $\mathrm{vHC}$ cases. $\mathbf{G}, \boldsymbol{H}$, Representative photomicrographs show virus density in right RSP cortex. $\boldsymbol{I}$, A comparison of infection densities confirms disynaptic input to $\mathrm{VHC}$ comes primarily from IL, whereas input to $\mathrm{dHC}$ comes from dorsal pregenual anterior cingulate and the RSP. Error bars indicate SEM. Cg1, Cingulate area 1; L0, lateral orbital cortex; M0, medial orbital cortex; V0, ventral orbital cortex; DL0, dorsolateral orbital cortex; RSD, retrosplenial cortex (dysgranular layer); RSG, retrosplenial cortex (granular layer).

labeling was confined to the ventral region of the PL (vPL) and especially the IL cortex on the ventromedial wall (compare Fig. 3, $C$ and $D)$. Despite some variability in the $\mathrm{vHC}$ injection sites, the labeling patterns were highly similar. For example, although the most ventrally located injection site (i.e., case G17) showed a restricted pattern of infection in the ventral prefrontal cortex (Fig. 3B, yellow dots), a similar infection pattern was observed in cases with nonoverlapping injection sites (e.g., G41 and G42). 
Furthermore, as can be seen in Figure 3, the distribution of labeling showed little contrast between layers. The prefrontal labeling is suggestive of deeper layers in some cases (e.g., case G44) consistent with a thalamic relay, but then suggestive of superficial layers in other cases (e.g., cases G30 and G29), indicating an entorhinal relay, thereby preventing a clear laminar analysis of the infected neurons (Burwell and Amaral, 1998; McKenna and Vertes, 2004). However, on the basis of infection density alone, there was a distinct dorsal-to-ventral division in the medial prefrontal cortex, which gave rise to projections that corresponded to the dorsal-to-ventral divisions of the hippocampus.

\section{Labeling in the retrosplenial cortex}

The most striking difference between the vHC and $\mathrm{dHC}$ cases at $60 \mathrm{~h}$ was the pattern of infection in the RSP cortex (Figs. $3 E, F$ ). In all $\mathrm{dHC}$ cases, prominent labeling was present throughout the entire rostrocaudal extent of the RSP cortex, which invaded both granular and dysgranular subdivisions. Although the distribution of labeling in animals overlapped into both superficial and deep layers, there was an apparent tendency for one case (G30) to show superficial labeling indicating a potential relay in the entorhinal cortex (Fig. 3E). There was less segregation for the other two cases (G44 and G29), both of which showed strong labeling that was dispersed throughout the entire RSP region. In marked contrast, there was a virtual absence of labeling in the RSP cortex for all animals with vHC injections, with only one case (G42) showing very limited infection in the dysgranular subdivision (Fig. 3F).

Together, these data suggest that the prefrontal cortex provides strong disynaptic input to both ventral and dorsal regions of the hippocampus, with $\mathrm{dHC}$ receiving more (indirect) input from dorsomedial (pregenual) regions, $\mathrm{vHC}$ receiving more input from ventromedial (infralimbic) regions, and the two hippocampal subdivisions receiving roughly equal input from the orbitofrontal cortex. Furthermore, only the dHC received disynaptic input from the retrosplenial cortex (Fig. 3I).

\section{Monosynaptic transport to thalamus and entorhinal cortex (48 h survival)}

Forty-eight hours after PRV-Bartha injections into the dorsal and ventral hippocampus, large numbers of retrogradely infected neurons were observed in distinct regions of both the thalamus and the entorhinal cortex. The labeling differed substantially between the $\mathrm{dHC}$ and $\mathrm{vHC}$ injections, particularly in the thalamus where there was virtually no overlap, indicating that the thalamic innervation to the two areas originate in different nuclei (Wyss and Van Groen, 1992; Vertes et al., 2006). Similarly, the segregation of entorhinal labeling revealed distinct entorhinal projections to the dorsal and ventral hippocampal CA1 regions, in accordance with previous reports (Ruth et al., 1982, 1988; Witter et al., 1989; Dolorfo and Amaral., 1998a,b).

\section{Labeling in the thalamus}

In the thalamus, monosynaptic labeling following $\mathrm{dHC}$ injections was heaviest in the anterior thalamic group of nuclei, specifically the anteromedial (AM), followed by dense infection in the anterodorsal (AD) and anteroventral (AV) (Figs. 4A-D). The pattern of thalamic infection was stronger in the hemisphere ipsilateral to the injection site. There was sparse labeling in the midline thalamic nuclei including the reuniens ( $\mathrm{Re})$, rhomboid (Rh), and the sensory thalamic nuclei (medial geniculate nucleus). There was little if any infection within the mediodorsal complex of the thalamus or the motor, intralaminar, or reticular thalamic nuclei $48 \mathrm{~h}$ after inoculation.
In contrast, monosynaptic labeling following $\mathrm{vHC}$ injections was observed primarily in the midline nuclei (Figs. $4 E-H$ ). The most prominent labeling was in the Re followed closely by the paraventricular (PV) and paratenial (PT) nuclei. As with $\mathrm{dHC}$ injections, monosynaptic labeling in $\mathrm{vHC}$-injected cases was primarily ipsilateral to the hemisphere of the injection site. The number of labeled cells was higher rostrally than caudally within the Re, PV, and PT nuclei. There was sparse labeling in other midline thalamic structures, namely, the intermediodorsal and rhomboid nuclei, throughout the entire rostrocaudal extent of the thalamus. The specificity of midline Re, PV, and PT monosynaptic input to the $\mathrm{vHC}$ is supported by the virtual absence of infection at $48 \mathrm{~h}$ in other thalamic structures, including the anterior and mediodorsal complexes (i.e., association nuclei), the ventral and lateral group of nuclei (motor nuclei), the intralaminar group, and the reticular nucleus. Figure $4 I$ summarizes the specificity and density of thalamic infection for all $\mathrm{dHC}$ and $\mathrm{vHC}$ cases. These data indicate that the $\mathrm{dHC}$ receives its input primarily from the anterior group of thalamic nuclei, whereas the $\mathrm{vHC}$ receives its thalamic input primarily from midline nuclei.

\section{Labeling in the entorhinal cortex}

Figure 5 shows the overall distribution of retrogradely infected cells in the dorsolateral and ventromedial areas of the entorhinal cortex after $48 \mathrm{~h}$. Consistent with previous studies, we found that cells located laterally in the entorhinal cortex projected to the $\mathrm{dHC}$, whereas cells located more medially in the entorhinal cortex projected to the vHC (Ruth et al., 1982, 1988; Witter et al., 1989; Dolorfo and Amaral, 1998a,b). Specifically, in all animals with $\mathrm{dHC}$ injections, there was dense labeling in the dorsolateral part of the entorhinal cortex (DLE). There was also considerable labeling in the perirhinal (PRh) and ectorhinal (Ect) cortex, both of which dorsally bound the dorsolateral entorhinal area. A contrasting pattern of infection was observed in vHC cases, all of which showed significant retrograde transport to the rostral portion of the caudomedial segment of the entorhinal cortex (areas dorsal intermediate entorhinal, DIE; ventral intermediate entorhinal, VIE; medial entorhinal, ME), which was substantially decreased in all $\mathrm{dHC}$ cases. Due to the difficulty in obtaining sections at the extreme caudal pole, we are unable to report the pattern of infection observed in the area known as the dorsocaudal medial entorhinal cortex (Witter et al., 2000; Hafting et al., 2005). Several studies using monosynaptic tracers have shown that this extreme caudal zone of the entorhinal cortex connects densely with the dorsal half of the hippocampus (Dolorfo and Amaral, 1998a,b; Witter et al., 2000). As Figure $5 C$ summarizes, however, there is a clear spatial segregation of labeling in the entorhinal cortex for the $\mathrm{dHC}$ and $\mathrm{vHC}$ groups, distinguishing the regions that give rise to the projections from the dorsolateral portions of the entorhinal cortex relative to the rostral caudomedial portion of the entorhinal cortex. Overall, this distribution of labeling was observed primarily on the side ipsilateral to the injection.

\section{Other structures labeled after dorsal and ventral hippocampal injections}

While this study focuses on monosynaptic transport to the thalamus and entorhinal cortex and disynaptic transport to the limbic cortex, we also observed labeling in several other brain regions, which did not differ according to the division of the hippocampus that was injected. For example, significant firstorder infected neurons were observed in the lateral hypothalamus, the septal nuclei (lateral, medial, and diagonal band), the supramamillary nuclei and the claustrum. Injections in the vHC 

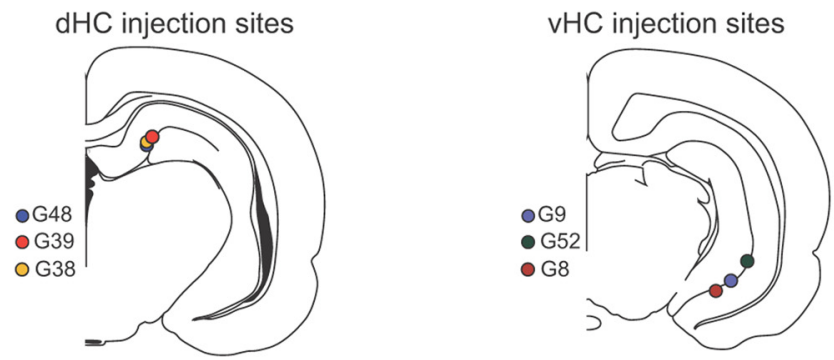

dHC monosynaptic labeling
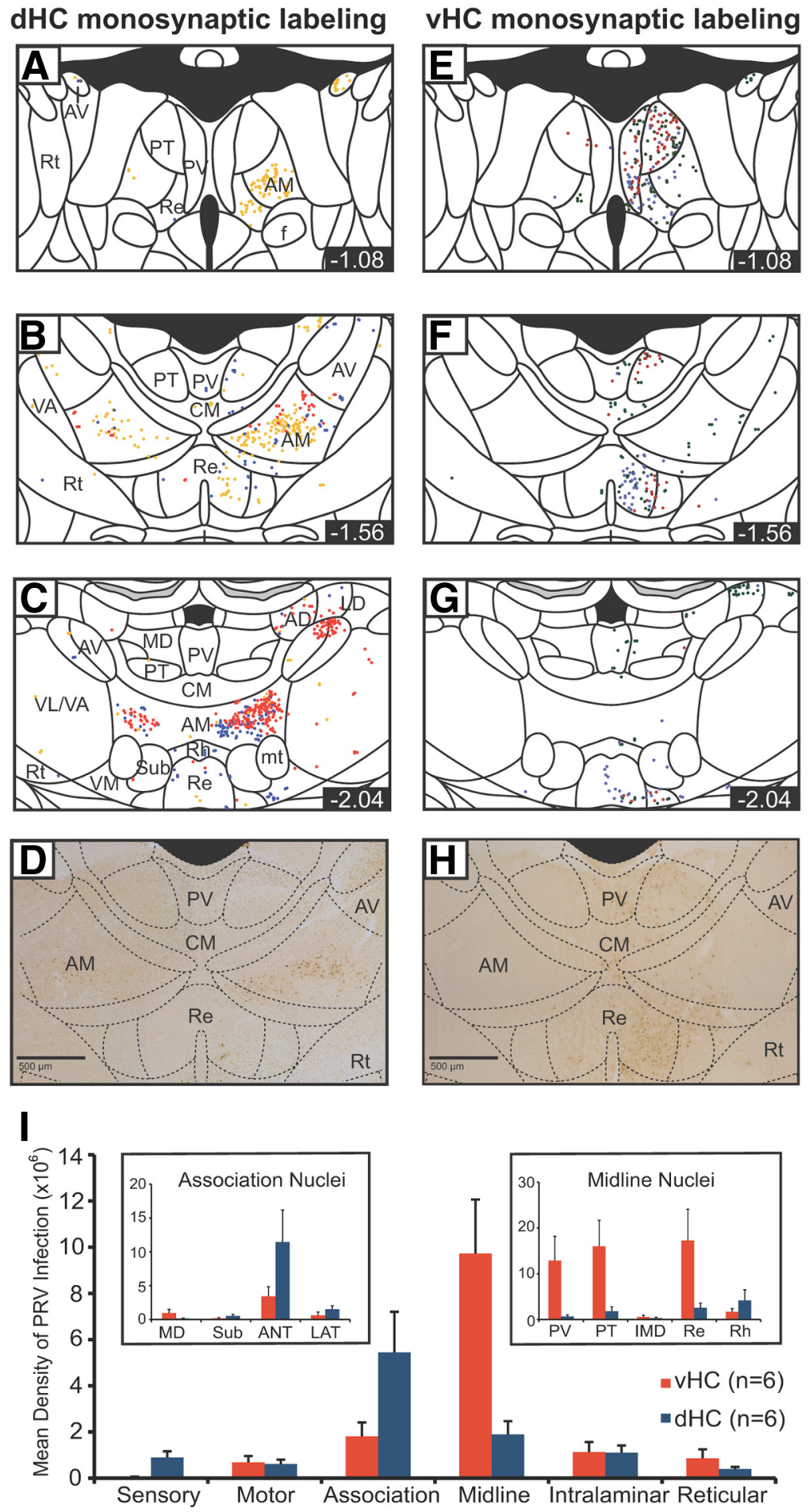

Figure 4. Pattern of PRV-Bartha infection in the thalamus $48 \mathrm{~h}$ after inoculation. Colors represent different animals. $\boldsymbol{A}-\boldsymbol{C}$, PRV-Bartha injections in the $\mathrm{dHC}$ resulted in thalamic infection that was localized in the anterior group of thalamic nuclei, namely, alone gave rise to monosynaptic labeling that was confined to the basolateral and basomedial amygdala and the anterior hypothalamus, whereas injections in the $\mathrm{dHC}$ gave rise to dense monosynaptic labeling in the perirhinal cortex. The posterior hypothalamus showed only disynaptic labeling, and more strongly following $\mathrm{dHC}$ than vHC injections. Finally, in all cases, there was an absence of monosynaptic and disynaptic labeling in all basal ganglia structures including the nucleus accumbens (core and shell), caudate putamen, globus pallidus, subthalamic nucleus, and substantia nigra. Nor was there labeling in the mammillary bodies.

\section{Discussion}

We have demonstrated parallel disynaptic pathways from the limbic and prefrontal cortex to the dorsal and ventral divisions of the hippocampus, with potential relays in the thalamus and entorhinal cortex. Previous studies have shown that the hippocampus sends direct projections to a number of the areas we identified, including the retrosplenial, medial prefrontal, and orbital cortex (Swanson, 1981; Wyss and Van Groen, 1992; Hoover and Vertes, 2007). The present findings demonstrate that these direct connections are reciprocated by disynaptic pathways, thereby completing an anatomical loop. Our study focused on the septotemporal poles of the hippocampus and demonstrate distinct parallel routes, and possibly

$\longleftarrow$

the $A M, A D$, and $A V$, and primarily ipsilateral to the hemisphere of the injection site. Note the paucity of labeling in the midline Re, PT, and PV nuclei, which by comparison was prominent in cases with PRV-Bartha injections in the VHC. E-G, Labeling in the midline nuclei was more rostral than caudal, and ipsilateral to the side of the injection in the $\mathrm{vHC} . \boldsymbol{D}, \boldsymbol{H}$, Representative photomicrographs ( $10 \times$ magnification) show infected cells in the thalamus following virus injection in $\mathrm{dHC}(\boldsymbol{D})$ and $\mathrm{vHC}(\boldsymbol{H})$. I, A quantitative comparison of infection densities between thalamic groups confirms that virus injected into the $\mathrm{dHC}$ transports monosynaptically to the association group of nuclei, whereas for the vHC injections, the virus transports to the midline thalamic nuclei. Insets show the density of infection for specific midline and association nuclei. The anterior group of nuclei (ANT) includes $A M, A D$, and AV. The lateral group of nuclei (LAT) includes the laterodorsal (LD) and lateral posterior (LP). Error bars indicate SEM. CL, Centrolateral; CM, centromedial; f, fornix; IMD, intermediodorsal; MD, mediodorsal; mt, mamillothalamic tract; PC, paracentral; Po, posterior thalamic nucleus; Rt, reticular; Sub, submedial; VA, ventral anterior; VL, ventrolateral; VM, ventromedial; VPM, ventral posteromedial. Approximate anterior-posterior levels and abbreviations are taken from Paxinos and Watson (2005). Divisions for sensory, motor, association, midline, and intralaminar groups are according to Groenewegen and Witter (2004). 
A

dHC monosynaptic labeling
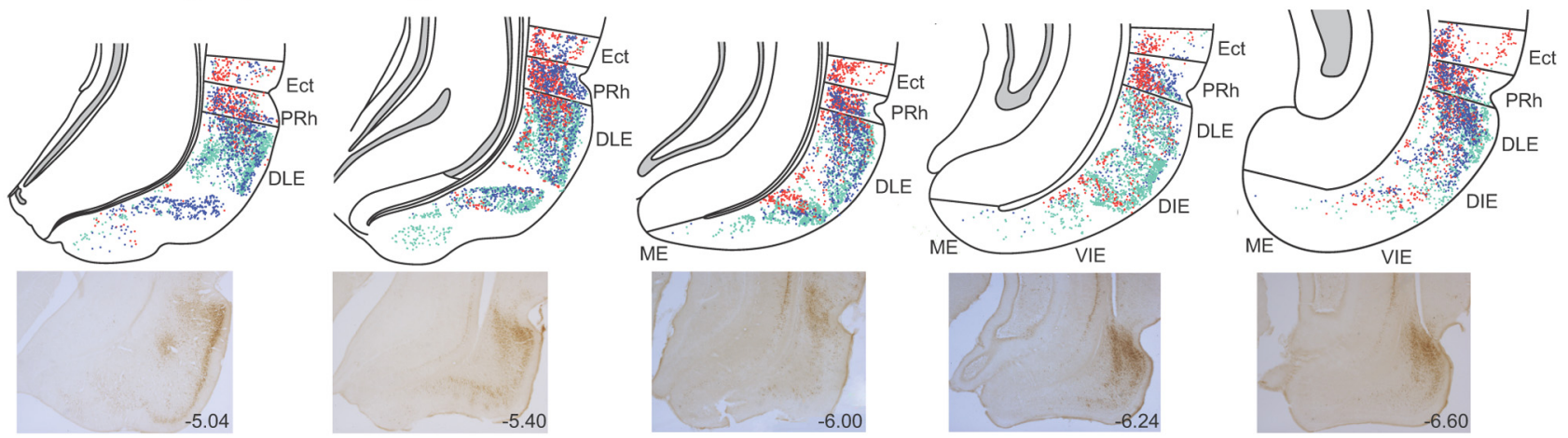

B

\section{vHC monosynaptic labeling}
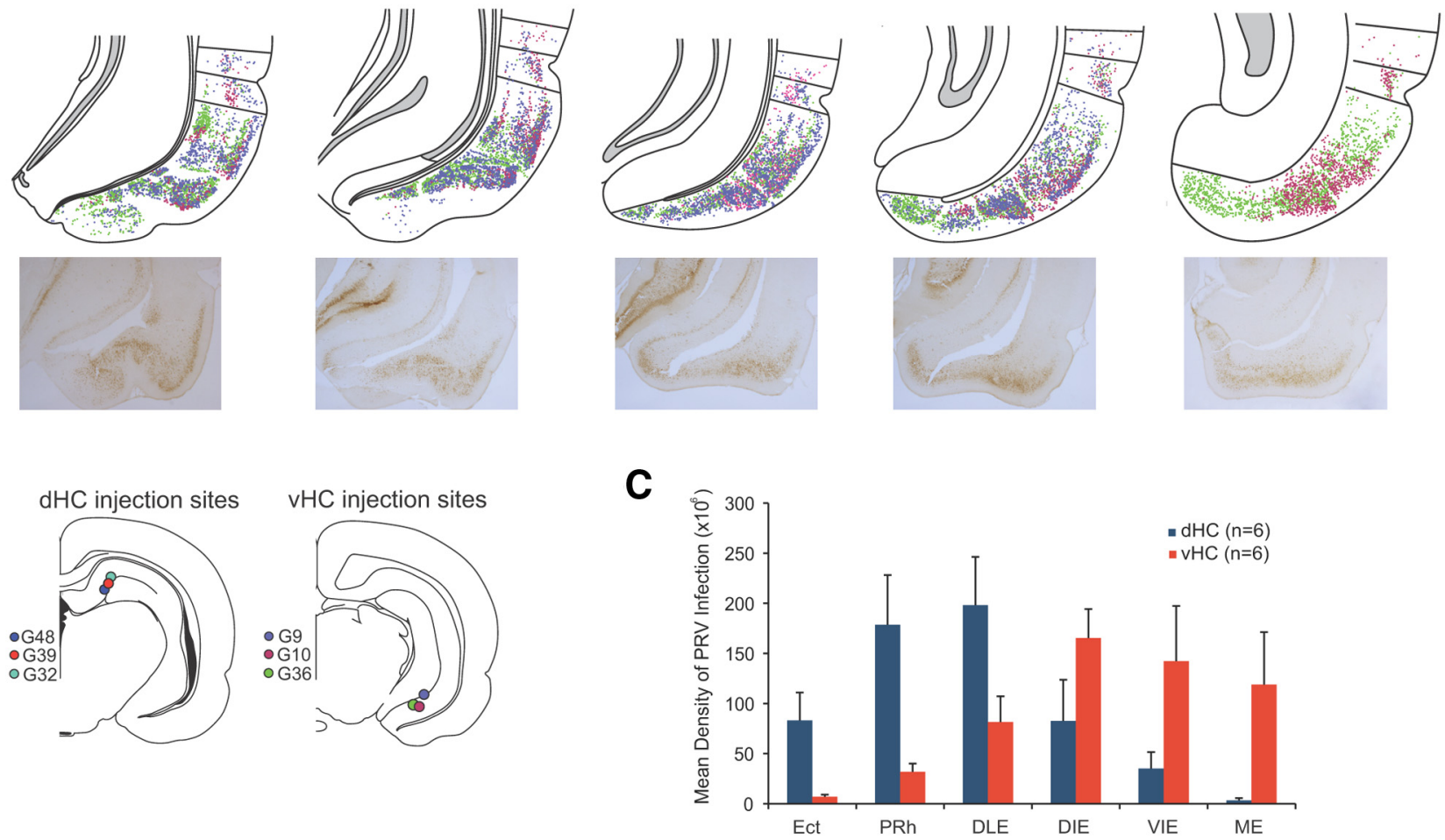

Figure 5. $\quad A, B$, Distribution of positive PRV-Bartha-infected cells in the entorhinal cortex cortex $48 \mathrm{~h}$ after inoculation following injections in the $\mathrm{dHC}(\boldsymbol{A})$ and the $\mathrm{vHC}(\boldsymbol{B})$. Colors represent different animals. In both cases, there is some overlap in labeled neurons in the dorsolateral portion of the entorhinal cortex (area DLE). In dHC cases, note how the pattern of labeling remains dorsal in the DLE and overlaps with the PRh and Ect. In VHC cases, the infection is confined to the ventromedial extent of entorhinal cortex, where it includes the rostral portion of the caudomedial entorhinal cortex (areas DIE, VIE, and ME). Photomicrographs ( $2.5 \times$ magnification) show positive PRV-Bartha cells in subfields of the entorhinal cortex. C, A quantification of the infection densities confirms that the dorsolateral portions of the entorhinal cortex give rise to first-order projections to the $\mathrm{dHC}$, and that the rostral caudomedial portion of the entorhinal cortex projects to the vHC. Error bars indicate SEM.

parallel loops, underlying corticohippocampal interaction (see Fig. 6). While the present study did not investigate the anatomical connections of intermediate sites along the septotemporal axis (Cenquizca and Swanson, 2007), an analogous pattern of connections along the intermediate zone might reflect a general anatomical relationship between the hippocampus, thalamus, entorhinal cortex, and limbic cortex. Different positions along this axis are thought to contribute to different aspects of behavior (Bast et al., 2009; but see Jarrard et al., 2012). The remaining discussion focuses on the specific anatomical circuits investigated in this study, touching on the functional specialization of each.

\section{Ventral hippocampal circuit}

Disynaptic labeling following injections into the vHC was most pronounced in the ventral prefrontal cortex (ventral PL, IL) and the neighboring orbital areas. These projections, together with the known projections from $\mathrm{vHC}$ to these areas, may constitute a functional loop, which we refer to here as the ventral hippocampal circuit. Note that with disynaptic labeling it is impossible to unambiguously identify which monosynaptically labeled area serves as the neural relay, an inherent limitation of this approach. Thus, in theory, either the midline thalamus or the entorhinal cortex could serve as the relay for this corticohippocampal pathway. However, recent evidence suggests that lesions to the mid- 


\section{Inputs to dorsal hippocampus}

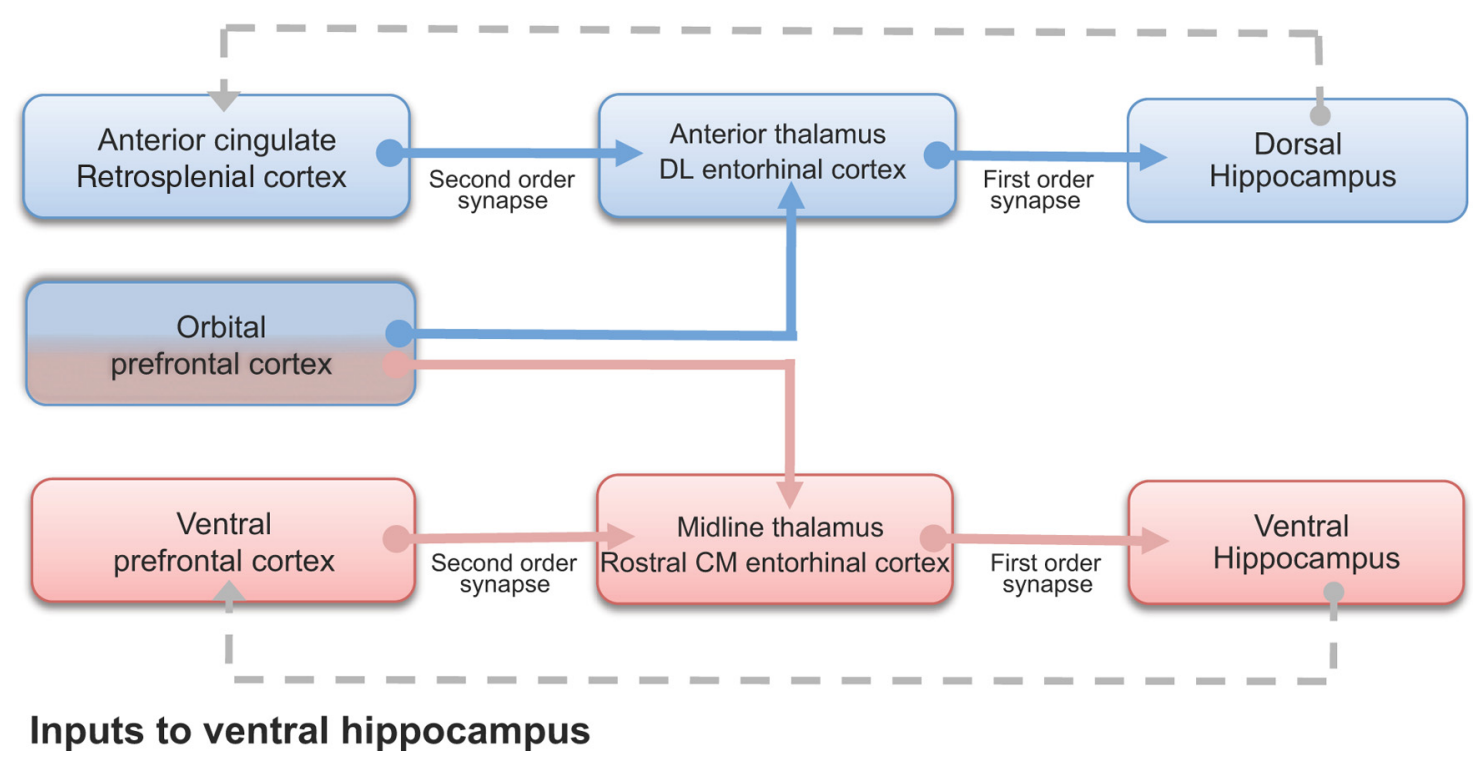

Figure 6. Illustration of first- and second-order inputs to dorsal and ventral hippocampus as shown in this study. The ventral prefrontal cortex connects disynaptically with the vHC via relays in the midline thalamus or rostral caudomedial (CM) entorhinal cortex (solid pink line). In contrast, inputs to the $\mathrm{dHC}$ involve relays in the anterior thalamic nuclei and the dorsolateral (DL) entorhinal cortex (solid blue line). The orbital prefrontal cortex provides second-order input to both dorsal and ventral divisions of the hippocampus. Direct hippocampal input to anterior cingulate, retrosplenial, medial prefrontal, and orbital prefrontal cortex has been shown previously (dashed gray line) (Swanson and Cowen, 1977; Swanson, 1981; Van Groen and Wyss, 1990; Jay and Witter, 1991; Wyss and Van Groen, 1992; Verwer et al., 1997; Hoover and Vertes, 2007).

line thalamic Re produce disinhibitory effects on behavior (Dolleman-van der Weel et al., 2009; Prasad et al., 2013) that closely resemble those of $\mathrm{vHC}$ and ventral prefrontal lesions (Chudasama et al., 2003; Abela et al., 2013) or following hemispheric disconnection of the two structures (Chudasama et al., 2012). While this evidence might favor the prospect that the midline thalamus is the critical relay in this circuit, we aim to test this hypothesis explicitly in future studies; there is at least one piece of evidence that implicates the entorhinal cortex in prefrontal executive function (see Oswald et al., 2001). Moreover, while a thorough laminar analysis was outside the scope of our study, it was clear that some of the labeled neurons were in the superficial layers of the prefrontal cortex. Since superficial layers do not project to the thalamus, it is likely that in these cases, the entorhinal cortex is the most likely relay (Burwell and Amaral, 1998; McKenna and Vertes, 2004).

Our monosynaptic results are consistent with previous studies using conventional tracers in identifying Re, PV, and PT as the main nuclei sending projections, with the projections being mainly ipsilateral and originating in the most rostral portion of the nuclei (Dolleman-Van Der Weel and Witter, 1996). Thus, one potential disynaptic pathway, which has been postulated previously (Vertes, 2006), runs from the ventral prefrontal cortex through the midline thalamus to the vHC. It is worth noting, however, that the Rh nucleus, previously found to project to certain parts of the vHC (Berendse and Groenewegen, 1991), was labeled sparingly in this study. Moreover, unlike Vertes et al. (2006), we did not observe many labeled neurons in the Re and $\mathrm{Rh}$ after injections into the $\mathrm{dHC}$. While it is possible that the density of fibers from the Rh to dorsal or ventral regions of the hippocampus were insufficient for the virus to initiate a productive viral uptake, it is more likely that our restricted pattern of retrograde labeling was due to the small injection site, which was localized within the extreme vicinity of the temporal pole. When retrograde tracers are injected into the intermediate zone of the
CA1 field, diffuse areas of the Re including its caudal sector are labeled significantly (Dolleman-Van Der Weel and Witter, 1996). The current data clearly demonstrate, however, that ventral prefrontal input to the $\mathrm{vHC}$ is relayed almost exclusively by the rostral Re, not the Rh.

The midline thalamic relay may also mediate prefrontalhippocampal communication related to anxiety and fear, as both structures have been implicated in affective processing (SierraMercado et al., 2011). Here the PV and possibly PT are likely to play a more significant role as a relay than the Re (Beck and Fibiger, 1995; Otake and Nakamura, 1995). Due to their small size, little is known about the functional contributions of PV and its neighboring PT thalamic nucleus, whose major output is the ventral striatum (Kelley and Stinus, 1984). The labeling observed in PV and PT in the present study suggests that these areas, in addition to mediating corticostriatal interaction (Groenewegen and Berendse, 1994), may play a role in mediating corticohippocampal interaction.

\section{Dorsal hippocampal circuit}

Injections in the $\mathrm{dHC}$ revealed patterns of monosynaptic and disynaptic labeling that were distinct from the vHC injections. Two areas that were prominently labeled following injections in the $\mathrm{dHC}$, but not substantially in the $\mathrm{vHC}$, were the anterior thalamic group of nuclei (monosynaptic) and RSP cortex (disynaptic). The infection in the RSP cortex was marked, extending along its entire rostrocaudal length, which occupies half the length of the rat cerebrum.

There is an extensive literature on how any or all of the monosynaptically labeled areas (anterior thalamus, entorhinal cortex, and perirhinal cortex) serve similar or complementary functions in spatial cognition (for review, see Aggleton et al., 2010; Aggleton, 2012). For example, rats with RSP lesions are impaired in tests of spatial memory, as are rats with anterior thalamic lesions (Vann and Aggleton, 2002; Jenkins et al., 2004). Both RSP cortex and 
anterior thalamic nuclei contain head-direction cells (Chen et al., 1994; Taube, 1995). The RSP cortex projects directly to the entorhinal and perirhinal cortex, both of which project to the dHC (Wyss and Van Groen, 1992). Thus, both entorhinal and perirhinal cortex may act as potential relays to the $\mathrm{dHC}$. The anterior thalamus is also a likely candidate, since it is known to receive input from the RSP cortex (Van Groen and Wyss, 2003). Moreover, previous disconnection studies have shown that the RSP cortex, anterior thalamus, and hippocampus interact to support spatial learning and memory (Sutherland and Hoesing, 1993; Warburton et al., 2001). Thus, the prominent indirect projections from the RSP cortex to the hippocampus featured in the dorsal hippocampal circuit are likely to be transmitted through synapses in temporal cortex, anterior thalamus, or both.

\section{Implications for understanding hippocampal contribution to behavior}

Our results show substantial segregation in the circuits associated with two regions of the hippocampus separated by several millimeters along its longitudinal extent. Each involves the orbital cortex, along with distinct regions of the limbic cortex, thalamus, and entorhinal cortex. We speculate that these results represent a more general pattern of interaction between the hippocampus and cortex, whose specific cortical and thalamic components vary gradually along the septotemporal hippocampal axis.

Of particular interest is the notion of the thalamus, part of the diencephalon, as a relay between the cortex and hippocampus, two prominent regions of the telencephalon. At present, there is much interest in the potential role of the thalamus as a mediator of corticocortical interactions (Sherman, 2007). It is intriguing to consider that the corticohippocampal relays suggested in this study may reflect an analogous pattern of connections. In fact, it is possible that the patterns of $\mathrm{vHC}$ and $\mathrm{dHC}$ labeling in the cortex and thalamus are two specific examples of a more general pattern of corticothalamic relays to the hippocampus, with a topological progression in each of the areas involved. In this scenario, input to the $\mathrm{dHC}$ originates in posterior and dorsal portions of the limbic cortex and passes through a synapse in the anterior thalamus, whereas input to the $\mathrm{vHC}$ originates in the anterior and ventral portions of the limbic cortex and passes through a synapse within certain midline thalamic nuclei. Whether injections made in intermediate levels of the hippocampus would show labeling in cortical and thalamic structures in accordance with a consistent topological relationship between these structures is a topic for future study.

The interplay between the cortex and thalamus has been considered in human imaging studies, where in spatial navigation tasks the RSP cortex and hippocampal formation are often engaged. The same two structures belong to the so called "default mode" network, defined as those areas showing diminished activity levels during a task relative to a resting state baseline (Maguire, 2001). It is notable that even in the absence of a task, this network shows spontaneous activity covariation that is often interpreted as indicating functional, and possibly anatomical, connections (Greicius et al., 2009). Our data provide a broader anatomical framework for understanding the interaction between medial cortical areas and the hippocampus, pointing to bidirectional communication: a direct projection from the hippocampus to the cortex, and a disynaptic projection from the cortex to the hippocampus, via a relay.

\section{References}

Abela AR, Chudasama Y (2013) Dissociable contributions of the ventral hippocampus and orbitofrontal cortex to decision-making with a delayed or uncertain outcome. Eur J Neurosci 37:640-647. CrossRef Medline

Abela AR, Dougherty SD, Fagen ED, Hill CJR, Chudasama Y (2013) Inhibitory control deficits in rats with ventral hippocampal lesions. Cereb Cortex, in press.

Aggleton JP (2012) Multiple anatomical systems embedded within the primate medial temporal lobe: Implications for hippocampal function. Neurosci Biobehav Rev 36:1579-1596. CrossRef Medline

Aggleton JP, O'Mara SM, Vann SD, Wright NF, Tsanov M, Erichsen JT (2010) Hippocampal-anterior thalamic pathways for memory: uncovering a network of direct and indirect actions. Eur J Neurosci 31:2292-2307. CrossRef Medline

Amaral DG (1993) Emerging principles of intrinsic hippocampal organization. Curr Opin Neurobiol 3:225-229. CrossRef Medline

Amaral DG, Witter MP (1989) The three-dimensional organization of the hippocampal formation: a review of anatomical data. Neuroscience 31: 571-591. CrossRef Medline

Bannerman DM, Yee BK, Good MA, Heupel MJ, Iversen SD, Rawlins JN (1999) Double dissociation of function within the hippocampus: a comparison of dorsal, ventral, and complete hippocampal cytotoxic lesions. Behav Neurosci 113:1170-1188. CrossRef Medline

Bast T, Wilson IA, Witter MP, Morris RG (2009) From rapid place learning to behavioral performance: a key role for the intermediate hippocampus. PLoS Biol 7:e1000089. Medline

Beck CH, Fibiger HC (1995) Conditioned fear-induced changes in behavior and in the expression of the immediate early gene c-fos: with and without diazepam pretreatment. J Neurosci 15:709-720. Medline

Berendse HW, Groenewegen HJ (1991) Restricted cortical termination fields of the midline and intralaminar thalamic nuclei in the rat. Neuroscience 42:73-102. CrossRef Medline

Burwell RD, Amaral DG (1998) Cortical afferents of the perirhinal, postrhinal, and entorhinal cortices of the rat. J Comp Neurol 398:179-205. CrossRef Medline

Card JP, Rinaman L, Lynn RB, Lee BH, Meade RP, Miselis RR, Enquist LW (1993) Pseudorabies virus infection of the rat central nervous system: ultrastructural characterization of viral replication, transport, and pathogenesis. J Neurosci 13:2515-2539. Medline

Carr DB, O'Donnell P, Card JP, Sesack SR (1999) Dopamine terminals in the rat prefrontal cortex synapse on pyramidal cells that project to the nucleus accumbens. J Neurosci 19:11049-11060. Medline

Cenquizca LA, Swanson LW (2007) Spatial organization of direct hippocampal field CA1 axonal projections to the rest of the cerebral cortex. Brain Res Rev 56:1-26. CrossRef Medline

Chen LL, Lin LH, Green EJ, Barnes CA, McNaughton BL (1994) Headdirection cells in the rat posterior cortex. I. Anatomical distribution and behavioral modulation. Exp Brain Res 101:8-23. CrossRef Medline

Chen S, Yang M, Miselis RR, Aston-Jones G (1999) Characterization of transsynaptic tracing with central application of pseudorabies virus. Brain Res 838:171-183. CrossRef Medline

Chudasama Y, Passetti F, Rhodes SEV, Lopian D, Desai A, Robbins TW (2003) Dissociable aspects of performance on the 5-choice serial reaction time task following lesions of the dorsal anterior cingulate, infralimbic and orbitofrontal cortex in the rat: differential effects on selectivity, impulsivity and compulsivity. Behav Brain Res 146:105-119. CrossRef Medline

Chudasama Y, Izquierdo A, Murray EA (2009) Distinct contributions of the amygdala and hippocampus to fear expression. Eur J Neurosci 30:2327-2337. CrossRef Medline

Chudasama Y, Doobay VM, Liu Y (2012) Hippocampal-prefrontal cortical circuit mediates inhibitory response control in the rat. J Neurosci 32: 10915-10924. CrossRef Medline

Dolleman-Van Der Weel MJ, Witter MP (1996) Projections from the nucleus reuniens thalami to the entorhinal cortex, hippocampal field CA1, and the subiculum in the rat arise from different populations of neurons. J Comp Neurol 364:637-650. CrossRef Medline

Dolleman-van der Weel MJ, Morris RG, Witter MP (2009) Neurotoxic lesions of the thalamic reuniens or mediodorsal nucleus in rats affect nonmnemonic aspects of watermaze learning. Brain Struct Funct 213:329-342. CrossRef Medline

Dolorfo CL, Amaral DG (1998a) Entorhinal cortex of the rat: topographic 
organization of the cells of origin of the perforant path projection to the dentate gyrus. J Comp Neurol 398:25-48. CrossRef Medline

Dolorfo CL, Amaral DG (1998b) Entorhinal cortex of the rat: organization of intrinsic connections. J Comp Neurol 398:49-82. CrossRef Medline

Enquist LW, Card JP (1996) Pseudorabies virus: a tool for tracing connections. In: Protocols for gene transfer in neuroscience: towards gene therapy of neurobiological disorders (Lowenstein PR, Enquist LW, eds), pp 333-348. New York: Wiley.

Fanselow MS, Dong HW (2010) Are the dorsal and ventral hippocampus functionally distinct structures? Neuron 65:7-19. CrossRef Medline

Floresco SB, Seamans JK, Phillips AG (1997) Selective roles for hippocampal, prefrontal cortical, and ventral striatal circuits in radial-arm maze tasks with or without a delay. J Neurosci 17:1880-1890. Medline

Greicius MD, Supekar K, Menon V, Dougherty RF (2009) Resting-state functional connectivity reflects structural connectivity in the default mode network. Cereb Cortex 19:72-78. Medline

Groenewegen HJ, Berendse HW (1994) The specificity of the "nonspecific" midline and intralaminar thalamic nuclei. Trends Neurosci 17:52-57. CrossRef Medline

Groenewegen HJ, Witter MP (2004) Thalamus. In: The rat nervous system, Ed 3 (Paxinos G, ed), pp 407-453. London: Elsevier Academic.

Hafting T, Fyhn M, Molden S, Moser MB, Moser EI (2005) Microstructure of a spatial map in the entorhinal cortex. Nature 436:801-806. CrossRef Medline

Heidbreder CA, Groenewegen HJ (2003) The medial prefrontal cortex in the rat: evidence for a dorso-ventral distinction based upon functional and anatomical characteristics. Neurosci Biobehav Rev 27:555-579. CrossRef Medline

Henriksen EJ, Colgin LL, Barnes CA, Witter MP, Moser MB, Moser EI (2010) Spatial representation along the proximodistal axis of CA1. Neuron 68:127-137. CrossRef Medline

Hoover WB, Vertes RP (2007) Anatomical analysis of afferent projections to the medial prefrontal cortex in the rat. Brain Struct Funct 212:149-179. CrossRef Medline

Howland JG, Harrison RA, Hannesson DK, Phillips AG. (2008) Ventral hippocampal involvement in temporal order, but not recognition, memory for spatial information. Hippocampus 18:251-257. CrossRef Medline

Jarrard LE, Luu LP, Davidson TL (2012) A study of hippocampal structurefunction relations along the septo-temporal axis. Hippocampus 22:680-692. CrossRef Medline

Jay TM, Witter MP (1991) Distribution of hippocampal CAl and subicular efferents in the prefrontal cortex of the rat studied by means of anterograde transport of Phaseolus vulgaris-leucoagglutinin. J Comp Neurol 313:574-586. CrossRef Medline

Jenkins TA, Vann SD, Amin E, Aggleton, JP (2004) Anterior thalamic lesions stop immediate early gene activation in selective laminae of the retrosplenial cortex: evidence of covert pathology in rats? Eur J Neurosci 19: 3291-3304. CrossRef Medline

Kelley AE, Stinus L (1984) The distribution of the projection from the parataenial nucleus of the thalamus to the nucleus accumbens in the rat: an autoradiographic study. Exp Brain Res 54:499-512. Medline

Maguire EA (2001) The retrosplenial contribution to human navigation: a review of lesion and neuroimaging findings. Scand J Psychol 42:225-238. CrossRef Medline

Mariano TY, Bannerman DM, McHugh SB, Preston TJ, Rudebeck PH, Rudebeck SR, Rawlins JN, Walton ME, Rushworth MF, Baxter MG, Campbell TG (2009) Impulsive choice in hippocampal but not orbitofrontal cortex-lesioned rats on a nonspatial decision-making maze task. Eur J Neurosci 30:472-484. CrossRef Medline

McKenna JT, Vertes RP (2004) Afferent projections to nucleus reuniens of the thalamus. J Comp Neurol 480:115-142. CrossRef Medline

O’Donnell P, Lavín A, Enquist LW, Grace AA, Card JP (1997) Interconnected parallel circuits between rat nucleus accumbens and thalamus revealed by retrograde transynaptic transport of pseudorabies virus. J Neurosci 17:2143-2167. Medline

Oswald CJP, Yee BK, Rawlins JNP, Bannerman DB, Good M, Honey RC (2001) Involvement of the entorhinal cortex in a process of attentional modulation: evidence from a novel variant of an IDS/EDS procedure. Behav Neurosci 115:841-849. Medline

Otake K, Nakamura Y (1995) Sites of origin of corticotropin-releasing factor-like immunoreactive projection fibers to the paraventricular thalamic nucleus in the rat. Neurosci Lett 201:84-86. CrossRef Medline
Paxinos G, Watson C (2005) The rat brain in stereotaxic coordinates, Ed 5. New York: Elsevier Academic.

Pentkowski NS, Blanchard DC, Lever C, Litvin Y, Blanchard RJ (2006) Effects of lesions to the dorsal and ventral hippocampus on defensive behaviors in rats. Eur J Neurosci 23:2185-2196. CrossRef Medline

Pomeranz LE, Reynolds AE, Hengartner CJ (2005) Molecular biology of pseudorabies virus: impact on neurovirology and veterinary medicine. Microbiol Mol Biol Rev 69:462-500. CrossRef Medline

Prasad JA, Macgregor EM, Chudasama Y (2013) Lesions of the thalamic reuniens cause impulsive but not compulsive responses. Brain Struct Funct 218:85-96. Medline

Room P, Russchen FT, Groenewegen HJ, Lohman AH (1985) Efferent connections of the prelimbic (area 32) and the infralimbic (area 25) cortices: an anterograde tracing study in the cat. J Comp Neurol 242:40-55. CrossRef Medline

Ruth RE, Collier TJ, Routtenberg A (1982) Topography between the entorhinal cortex and the dentate septotemporal axis in rats: I. Medial and intermediate entorhinal projecting cells. J Comp Neurol 209:69-78. CrossRef Medline

Ruth RE, Collier TJ, Routtenberg A (1988) Topographical relationship between the entorhinal cortex and the septotemporal axis of the dentate gyrus in rats: II. Cells projecting from lateral entorhinal subdivision. J Comp Neurol 270:506-516. CrossRef Medline

Sesack SR, Deutch AY, Roth RH, Bunney BS (1989) Topographical organization of the efferent projections of the medial prefrontal cortex in the rat: an anterograde tract-tracing study with Phaseolus vulgaris leucoagglutinin. J Comp Neurol 290:213-242. CrossRef Medline

Sherman SM (2007) The thalamus is more than just a relay. Curr Opin Neurobiol 17:417-422. CrossRef Medline

Sierra-Mercado D, Padilla-Coreano N, Quirk GJ (2011) Dissociable roles of prelimbic and infralimbic cortices, ventral hippocampus, and basolateral amygdala in the expression and extinction of conditioned fear. Neuropsychopharmacology 36:529-538. CrossRef Medline

Small SA, Schobel SA, Buxton RB, Witter MP, Barnes CA (2011) A pathophysiological framework of hippocampal dysfunction in ageing and disease. Nat Rev Neurosci 12:585-601. CrossRef Medline

Sutherland RJ, Hoesing JM (1993) Posterior cingulate cortex and spatial memory: a microlimnology analysis. In: Neurobiology of cingulate cortex and limbic thalamus: a comprehensive treatise (Vogt B, Gabriel M, eds), pp 461-477. Boston: Birkhauser.

Swanson LW (1981) A direct projection from Ammon's horn to prefrontal cortex in the rat. Brain Res 217:150-154. CrossRef Medline

Swanson LW, Cowan WM (1977) An autoradiographic study of the organization of the efferent connections of the hippocampal formation in the rat. J Comp Neurol 172:49-84. CrossRef Medline

Taube JS (1995) Head direction cells recorded in the anterior thalamic nuclei of freely moving rats. J Neurosci 15:70-86. Medline

Thompson RH, Swanson LW (2010) Hypothesis-driven structural connectivity analysis supports network over hierarchical model of brain architecture. Proc Natl Acad Sci U S A 107:15235-15239. CrossRef Medline

Van Groen T, Wyss JM (1990) The postsubicular cortex in the rat: characterization of the fourth region of the subicular cortex and its connections. Brain Res 529:165-177. CrossRef Medline

Van Groen T, Wyss JM (2003) Connections of the retrosplenial granular b cortex in the rat. J Comp Neurol 463:249-263. CrossRef Medline

Vann SD, Aggleton JP (2002) Extensive cytotoxic lesions of the rat retrosplenial cortex reveal consistent deficits on tasks that tax allocentric spatial memory. Behav Neurosci 116:85-94. CrossRef Medline

Vertes RP (2006) Interactions among the medial prefrontal cortex, hippocampus and midline thalamus in emotional and cognitive processing in the rat. Neuroscience 142:1-20. CrossRef Medline

Vertes RP, Hoover WB, Do Valle AC, Sherman A, Rodriguez JJ (2006) Efferent projections of reuniens and rhomboid nuclei of the thalamus in the rat. J Comp Neurol 499:768-796. CrossRef Medline

Verwer RW, Meijer RJ, Van Uum HF, Witter MP (1997) Collateral projections from the rat hippocampal formation to the lateral and medial prefrontal cortex. Hippocampus 7:397-402. CrossRef Medline

Warburton EC, Baird A, Morgan A, Muir JL, Aggleton JP (2001) The conjoint importance of the hippocampus and anterior thalamic nuclei for allocentric spatial learning: evidence from a disconnection study in the rat. J Neurosci 21:7323-7330. Medline

Witter MP, Groenewegen HJ (1984) Laminar origin and septotemporal dis- 
tribution of entorhinal and perirhinal projections to the hippocampus in the cat. J Comp Neurol 224:371-385. CrossRef Medline

Witter MP, Groenewegen HJ, Lopes da Silva FH, Lohman AH (1989) Functional organization of the extrinsic and intrinsic circuitry of the parahippocampal region. Prog Neurobiol 33:161-253. CrossRef Medline

Witter MP, Wouterlood FG, Naber P. A. Van Haeften T (2000) Anatomical organization of the parahippocampal-hippocampal network. Ann N Y Acad Sci 911:1-24. Medline
Wouterlood FG, Saldana E, Witter MP (1990) Projection from the nucleus reuniens thalami to the hippocampal region: light and electron microscopic tracing study in the rat with the anterograde tracer Phaseolus vulgaris-leucoagglutinin. J Comp Neurol 296:179-203. CrossRef Medline

Wyss JM, Van Groen T (1992) Connections between the retrosplenial cortex and the hippocampal formation in the rat: a review. Hippocampus 2:1-11. CrossRef Medline 